\title{
Evaluation of Chromosomal Aberrations and Micronuclei in Medical Workers Chronically Exposed to Low Dose Ionizing Radiation
}

\author{
${ }^{\square}$ Yanti Lusiyanti, Iin Kurnia, Viria Agesti Suvifan, Sardini, Sofiati Purnami, Nastiti \\ Rahajeng
}

DOI: 10.15294/biosaintifika.v9i3.12382

Center for Radiation Safety Technology and Metrology, National Nuclear Energy Agency (BATAN) Indonesia

\section{History Article}

Received 13 August 2017 Approved 10 November 2017 Published 31 December 2017

\section{Keywords}

Chromosome aberrations; Human lymphocytes; Ionizing radiation; Occupational exposure

\begin{abstract}
Medical workers representing the group is the most consistently are exposed to low doses of ionizing radiation, prolonged low-level ionizing radiation can induce chromosomal aberrations (CAs). This study would evaluate the cytogenetic effect using the CAs based on dicentric, and cytokinesis-blocked micronucleus (CBMN) assay on hospital workers. The exposed group dividedto Interventional and Diagnostic groups then compared to non exposed group. The accumulated absorbed doses calculated for the radiation workers were below $5 \mathrm{mSv}$. Blood samples were obtained from 29 samples of medical workers, and 15 samples of control. The Study showed that the frequency of dicentric chromosomes both in exposed and control were not found. In case of micronuclei, the mean frequencies were observed in exposed group that was $(19 \pm 6.22)$ and $(16.25 \pm 6.04)$ respectively and the control group was (10.4 \pm 7.79$)$. Frequency MN/1000 cell in the lymphocytes both in the two exposed group was relatively higher compared to control group. However the MN frequencies in all sample group was still in normal range. In this study chronic low radiation dose exposure in the hospital had no significant effect on chromosome aberration nor micronuclei. The benefit of the study is to enrich the potential usefulness of cytogenetic assay providing safety index in medical surveillance programs. The results suggest that education and retraining of staff concerning radiation safety guidelines need to be done to maintain the safety aspects of radiation.
\end{abstract}

\section{How to Cite}

Lusiyanti, Y., Kurnia, I., Suvifan, V. A., Sardini, S., Purnami, S., \& Rahajeng, N. (2017). Evaluation of Chromosomal Aberrations and Micronuclei in Medical Workers Chronically Exposed to Low Dose Ionizing Radiation. Biosaintifika: Journal of Biology \& Biology Education, 9(3), 585-591.

(C) 2017 Universitas Negeri Semarang
Correspondence Author:

Jl. Lebak Bulus Raya 49, Jakarta 12070

E-mail: k_lusiyanti@batan.go.id
p-ISSN 2085-191X

e-ISSN 2338-7610 


\section{INTRODUCTION}

Hospital staffs are an occupational group exposed to different agents suspected to induce genetic damage, such as ionizing radiation (x- and gamma- rays), radionuclides, cytostatic drugs, and anaesthetic gases, in which all of them have been investigated for their cytogenetic effect (Kasuba et al., 2008). Occupational radiation exposure is normally less than a few cGy per year. The International Commission on Radiological Protection (ICRP) has set the following limits on exposure to ionizing radiation: the general public shall not be exposed to more than $1 \mathrm{mSv}$ per year (over and above natural background) and occupational exposure shall not exceed $20 \mathrm{mSv}$ per year. These limits exclude exposure due to background and medical radiation. The limit for normal occupational exposure is $0.05 \mathrm{~Sv} /$ year. Monitoring of personnel occupationally exposed to ionizing radiation consists of regular film dosimetric control and periodic health examination (UNSCEAR, 2000).

Chromosomal aberrations in peripheral blood lymphocytes have been used for many years to monitor human populations exposed to potential carcinogens including ionizing radiation. (Bonnasi, 2007). Ionizing radiation can induce various forms of DNA damage including the possibility of increasing the incidence of chromosomal aberrations (CAs) and micronuclei (MN). The analysis of dicentric and centric ring CAs has been the most sensitive biological method for radiation dose assessment for many years. Analysis of CAs and $\mathrm{MN}$ in peripheral blood lymphocytes has also been used for a long time to evaluate of exposures to various mutagens or carcinogens. Many cytogenetic studies have been conducted among hospital workers exposed to ionizing radiation (Boffetta et al., 2007; Dias et al., 2007and compare the results with 36 controls, using the chromosomal aberrations test (CA; Bonassi et al., 2007)although prospective cohort studies are needed to validate $\mathrm{MN}$ as a cancer risk biomarker. A total of 6718 subjects from of 10 countries, screened in 20 laboratories for MN frequency between 1980 and 2002 in ad hoc studies or routine cytogenetic surveillance, were selected from the database of the HUman MicroNucleus (HUMN. Observed increased rates of chromosomal aberrations are received by hospital workers exposed to ionizing radiation. A low, but statistically significant, increase in the rate of chromosomal aberrations in circulating lymphocytes among hospital workers with thyroid nodules was also observed in workers occupationally exposed to radiation.
The results of several follow-up studies have been published by Bouraoui et al. (2013)age and smoking habits was used. The clastogenic/aneugenic effect of IR was evaluated using the CBMN assay in combination with fluorescence in situ hybridization with human pan-centromeric DNA in all the exposed subjects and controls. Results: The study showed a significant increase of the micronucleus (MN and was reporting on a significant increase of the micronucleus frequency in the lymphocytes of the exposed workers compared to the control group. On the other hand, the proliferation of markers that can be used to evaluate general toxicity caused by radiation exposure is the Mitotic Index (MI) and Nuclear Division Index (NDI) used to define cell cycles progression of the lymphocytes after mitogenic stimulation in culture cells. Another cell proliferation used at the tissue level is the use of AgNORs staining techniques used to evaluate cell morphology and kinetics of biopsy results. Kurnia et al. (2012) reported that the AgNOR staining technique was effective to assess the proliferation rate in tissue biopsy of cancer patients. At present, the increasing application of radiation for medical purposes indicates the need to conduct cytogenetic analysis in order to evaluate the level of chronic exposure. Although the baseline frequency of CAs from the normal population has a wide range of variation which might reflect interlaboratory differences in culture conditions or characteristics of the sample (Zakeri \& Hirobe, 2010)36 nuclear medicine physicians and 33 conventional radiologists were included in this study, along with 35 healthy age- and sex-matched individuals as the control group. We used conventional metaphase chromosome aberration (CA. The purpose of the study was to assess occupationally induced chromosomal damage in medical workers who exposed to low levels of ionizing radiation using the cytogenetic endpoints of CAs and MN and also evaluate MI and NDI index. The results of this study are expected to emphasize the importance of biomonitoring aspects of health in implementing safety programs of radiation exposure.

\section{METHODS}

\section{Subjects and Sampling}

The sample group of hospital workers consisted of 29 exposed staff and according to the job classification of 13 as radiographer staff in the diagnostic division and 16 Interventional staff. The mean duration of occupational exposure to radiation respectively $16.41 \pm 9.94$ years (from 4 to 34 years) and the control staff consisted of 14 
unexposed individuals. Peripheral blood samples were collected by venipuncture using heparinized vacutainer tubes (BD Vacutainer systems). The study was approved by the Ethics Committee of the National Institute of Health Research and Development, the Indonesian Ministry of Health, number LB.02.01/5.2.KE.051/ 2015. Informed consent was obtained from all staff. A detailed questionnaire was used to get information on age and occupation.

\section{Dicentric Assay and Mitotic Index Evaluation (MI)}

Blood cultures were set up according to the IAEA standard procedures with minor modifications (IAEA 2011) as described in previous research (Lusiyanti et al., 2013) one $\mathrm{ml}$ of whole blood samples were cultured for 48 hours in the incubator at $37^{\circ} \mathrm{C}$ containing $5 \% \mathrm{CO}_{2}$. The culture medium consisted of $7.5 \mathrm{ml}$ of Roswell Park Memorial Institute (RPMI) 1640 supplemented with $20 \%$ heat-inactivated fetal bovine serum (FBS), 1\% streptomycin/penicillin, $2.5 \% \mathrm{ml}$ of phytohemagglutinin (PHA). Colchicine was added to the culture medium for the last 3 hours at a final concentration of $0.05 \mu \mathrm{g} / \mathrm{ml}$. The cells then were centrifuged for 10 minutes at $1500 \mathrm{rpm}$ and resuspended in $10 \mathrm{ml}$ of $0.075 \mathrm{M} \mathrm{KCl}$ (pre-warmed to $37^{\circ} \mathrm{C}$ ) for 25 minutes. The cells then were centrifuged again for 10 minutes at $1500 \mathrm{rpm}$ and re-suspended in $2 \mathrm{ml}$ of fresh fixative that was a mixture of methanol and acetic acid (3:1). The fixation step was repeated four times until white sediment was obtained. Fixed cells were dropped onto clean, wet slides, dried and stained with $4 \%$ Giemsa solution ( $\mathrm{pH}$ 6.8) for 10 minutes. Mitotic Index then was calculated based on the protocol in the IAEA publication as shown in Formula (1). Typically, 500 cells were counted for a full mitotic index analysis for each sample (Figure 1).

Mitotic Index $=(\#$ metaphases $) \times 100 \times 500$ (\#metaphases+blast)

\section{The cytokinesis-block micronucleus assay and Nuclear Division Index Evaluation}

Micronuclei were prepared in cytokinesisblocked cells using cytochalasin B following the method suggested by Fenech (2007) with minor modification as described in previous research (Lusiyanti et al., 2016). The cultures were incubated for $72 \mathrm{~h}$. After $44 \mathrm{~h}$ of incubation cytochalasin $\mathrm{B}$ (Sigma) was added to the cultures at a concentration of $6 \mu \mathrm{g} / \mathrm{ml}$ to block cytokinesis. The cells were collected by centrifugation, and treated with a mild hypotonic solution containing $0.075 \mathrm{M}$
$\mathrm{KCl}$ for $3 \mathrm{~min}$. After centrifugation and removal of the supernatant, the cells were fixed with a fresh mixture of methanol/acetic acid (3:1). Centrifugation and resuspension were carried out three times and the cells were then dropped on to clean slides for detection of micronuclei by conventional staining with 5\% Giemsa. At least 1000 binucleated cells were scored for each person for the presence of micronuclei according to the criteria by Fenech (2007). Nuclear Division Index (NDI) was calculated based on follows formula (2) where M1, M2, M3 and M4 were the proportion of mononucleated, binucleated, trinucleated and tetranucleated (Figure 2) and $\mathrm{N}$ is the total number of cells analyzed. $\mathrm{N}=1000$

$N D I=\frac{(M 1+2 M 2+3 M 3+4 M 4)}{N}$

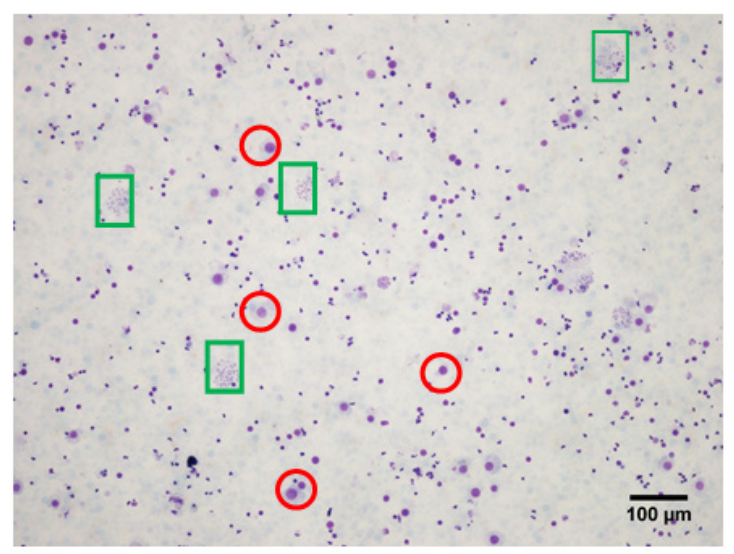

Figure 1. View of a typical lymphocyte culture slide. Red circles are nuclei counted as blasts, white circles are nuclei which are not counted, boxes are metaphase spreads (200x magnification).

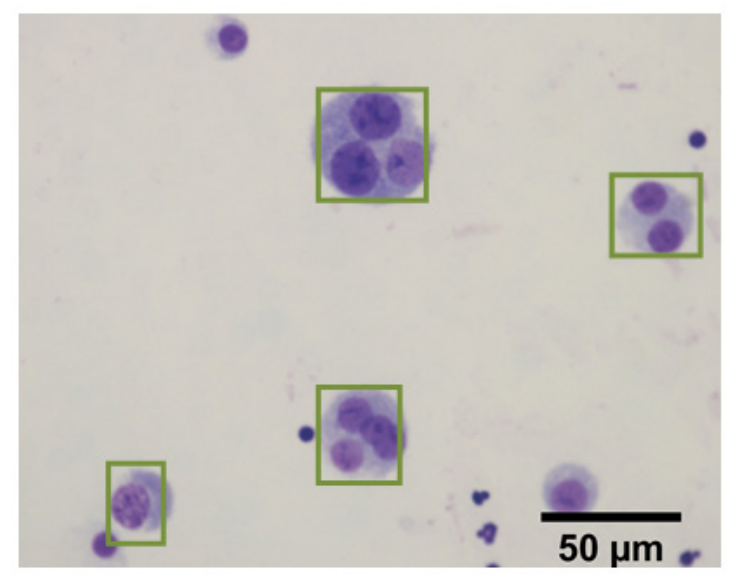

Figure 2. A microscopic view of Giemsa stained slide that containing the number of cells with one, two, three and four nuclei chromosome spread (boxes) for evaluation NDI (magnification 
of 400X).

\section{Statistical Analysis}

Unpaired t-test was used to compare the MI and NDI, and also the frequency of unstable CAs and micronuclei between exposed workers and control samples using SPSS 22.0 statistical software. The influence of micronuclei and exposure duration of employment were tested using the medical software.

\section{RESULTS AND DISCUSSION}

Cytogenetic analysis by mean CAs and MN in cytokinesis block (CBMN) in human peripheral blood lymphocytes is an important technique for risk assessment in occupational exposure. In this study, radiation workers chronically exposed to ionizing radiation have evaluated the frequencies of CAs, and MN. On the other hand in this study,tests of cell proliferating markers were done by using Mitotic Index (MI) and Nuclear Division Index (NDI). The mean MI and NDI among exposed group compared to control group were shown in Table 1.

MI and NDI are markers for estimating the general toxicity. The proportion of metaphase cells and binucleated cells may be used as a biomarker of the lymphocytes mitogen response, immune functions and cytostatic effects of various studied agents included the low radiation dose exposure (Eroğlu, 2011, Alaloc \& Eroğlu,2011). Table 1 showed that the MI of the exposed staff in diagnostic and interventional is slightly higher compared to control but statistically it is not significantly different. It means that chronic low radiation dose exposure in exposed staff has no significant effect on lymphocytes proliferation. Furthermore, larger sample number should be used in further research to ensure the effect of chronic low radiation dose exposure on lymphocytes proliferation. In this study a total of 11000 metaphases or on average about 250 cells (exposed group and control) were analyzed and the result showed that observation chromosome aberration such as dicentric and centric rings chromosome was not detected in all exposed and control staff. Similar results had been reported in another research concerning with the induction of chromosome based on dicentric type, reporting the absence of centric ring and dicentric chromosome. In fact at this level of exposure a very high number of scored metaphases was required in order to detect the presence of dicentric (Cardoso \& Peitl, 2001). Cigarran et al. (2001) also reported that no significant increase in chromosomal abnormalities in their study population as there was a wide variation in the individual frequencies. According to Terzoudi \& Pantelias (2006) the cytogenetic response to ionizing radiation is intrinsic for each individual so that radiosensitivity between individuals may be an effect due to differences in DNA repair capacity, which can be explained by specific mutations or polymorphism in DNA repair genes or alternatively may be linked to cell cycle and feedback control mechanism. Thieren et al. (2002) suggested that exposure to low radiation doses might induce inter-individual differences in susceptibility and the activation of DNA repair and the transcription of early response genes and stimulate DNA repair enzymes.

In case of micronuclei the observations of micronucleus in binucleate cells (BNC) frequencies were carried out in each of 1000 binucleate cells per sample. The mean frequencies and distribution of MN frequencies in between medical radiation workers group (Diagnostic and interventional) compared to control staff were shown in Table 2 and Figure 3.

The frequencies of $\mathrm{MN}$ in the exposed group (diagnostic and interventional) varied between each exposed in range of 6-24/1000 BNC and $11-27 / 1000 \mathrm{BNC}$ for diagnostic and interventional staff respectively, whereas in control staff in range of $1-23 / 1000 \mathrm{BNC}$ (Figure 3).

Table 1. The mean MI and NDI in radiation workers group compared to control group in hospital staff.

\begin{tabular}{lccccc}
\hline Group & $\begin{array}{c}\text { Number } \\
\text { of sub- } \\
\text { jects }\end{array}$ & $\begin{array}{c}\text { Age (yr) } \\
\mathrm{x}^{-} \pm \mathrm{SD} \\
(\%)\end{array}$ & $\begin{array}{c}\text { Duration of } \\
\text { employment } \\
(\mathrm{yr}) \mathrm{x}^{-} \pm \mathrm{SD}(\%)\end{array}$ & $\begin{array}{c}\text { Mean MI } \pm \\
\text { SD }(\%)\end{array}$ & $\begin{array}{c}\text { Mean NDI } \\
\pm \mathrm{SD}\end{array}$ \\
\hline Diagnostic & 13 & $42.31 \pm 11.76$ & $15.92 \pm 9.68$ & $10.05 . \pm 2.07$ & $1.32 \pm 0.14$ \\
Interventional & 16 & $47.88 \pm 11.42$ & $17.13 \pm 10.74$ & $10.82 \pm 1.98$ & $1.31 \pm 0.13$ \\
Control & 15 & $42.13 \pm 11.43$ & - & $9.16 \pm 2.69$ & $1.39 \pm 0.18$ \\
Total & 44 & & & & \\
\hline \multicolumn{5}{c}{ *Significant (P<0.05) compared to the control group } \\
\end{tabular}




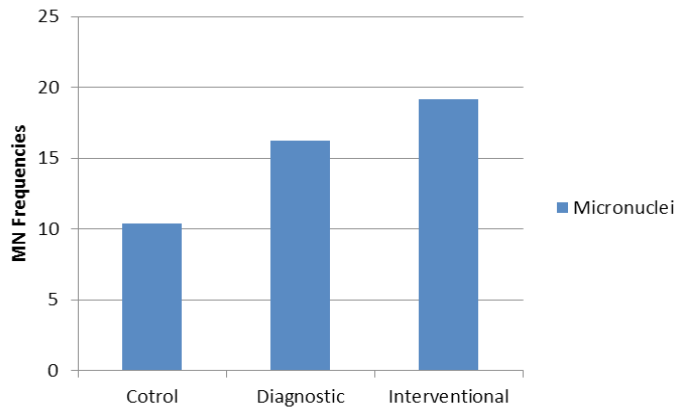

Figure 3. The mean frequencies of Micronuclei in lymphocytes from exposed group in medical workers, compared to control group.

According to the IAEA manual (2011), the $\mathrm{MN}$ frequencies in both exposed group and control group were still in normal range (1-36/1000 BNC) ( International Atomic Energy Agency, 2011) particularly when there are difficulties in interpreting the data, in cases where there is reason to believe that persons not wearing dosimeters have been exposed to radiation, in cases of claims for compensation for radiation injuries that are not supported by unequivocal dosimetric evidence, or in cases of exposure over an individual $\backslash$ u2019s working lifetime. The IAEA has maintained a long standing involvement in biological dosimetry commencing in 1978. This association has been through a sequence of coordinated research programmes (CRPs. In this study the existence of the variation in $\mathrm{MN}$ between individuals, according to Joseph et al. (2004), that a high individual variability exists as a consequence of intrinsic genomic instability in peripheral lymphocytes, which may be affected by the quality and the intensity of exposure in modulating the cellular's response to radiation injury. The lack of an increase in micronuclei frequency in the exposed population might indicate that the chronic doses received by the exposed subjects are either too low to be detected or the damage caused might have been repaired during the long span of time. (Cigarran et al,2001). Association based on the mean frequencies in both exposed group compared to control is shown in Figure 4.
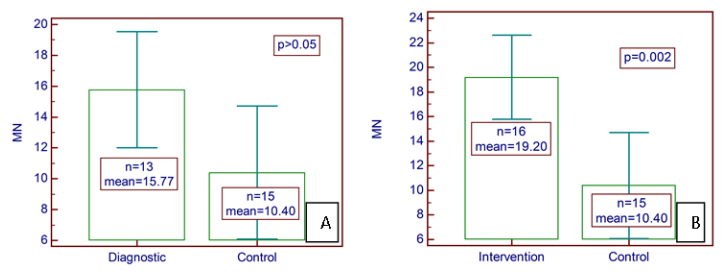

Figure 4. The mean frequencies of micronuclei in control subject compare to Diagnostic workers (A) and Interventional workers in Hospital (B).
In this study the mean frequencies of MN for the diagnostic and interventional groups were respectively $15.77 \pm 6.51$ and $19.20 \pm 6.42$. Whereas for the control staff was $(10.47 \pm 6.33)$, and showed significant differences $(\mathrm{P}=0.67)$. The higher frequencies of $\mathrm{MN}$ were found for radiation workers in Interventional staff. This was caused probably by the increase of chromosome damage that can be due to the accumulation of DNA damage by chronic exposure from gamma /or X-rays along the years of employment (Cardoso \& Peitl, 2001). Similar results had been reported in another research concerning to enhancement of $\mathrm{MN}$ frequencies using CBMN method where this was significantly higher in the exposed group than the control group (Zakeri \& Hirobe, 2010)36 nuclear medicine physicians and 33 conventional radiologists were included in this study, along with 35 healthy age- and sex-matched individuals as the control group. We used conventional metaphase chromosome aberration (CA. Related to job classification between two exposed group the mean frequencies on $\mathrm{MN}$ are shownin Figure 5.

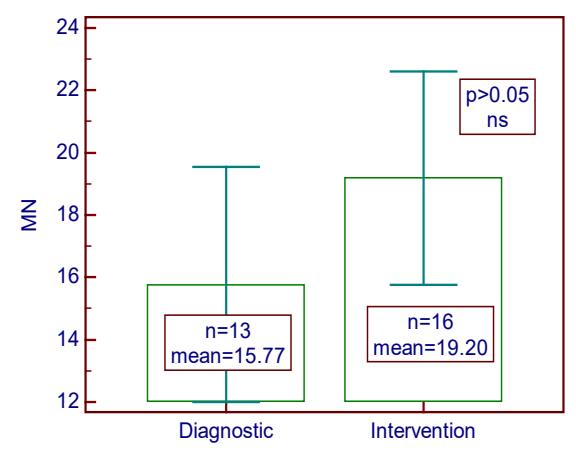

Figure 5. The mean frequencies of micronuclei in Diagnostic workers compare to Interventional workers in the hospital.

The higher mean frequencies were found in interventional staff compare to diagnostic staff. This finding is in agreement with other studies reporting from another researcher that was found no significant, increase in MN frequency in medical radiation workers (Maffei et al, 2002). The interventional group working in a high-volume catheterization laboratory had higher levels of $\mathrm{MN}$, when compared with diagnostic. Years of radiological practice were correlated with the $\mathrm{MN}$ value in the exposed group, which suggests the presence of cumulative damage (Andreassi et al., 2005). Furthermore in this study the $M N$ frequency in the exposed the groups based on the duration work length of employment as shown in Figure 6. The duration of exposure is expressed 
as length of employment, and in some cases, is not related to continuous exposure to ionizing radiation during the years

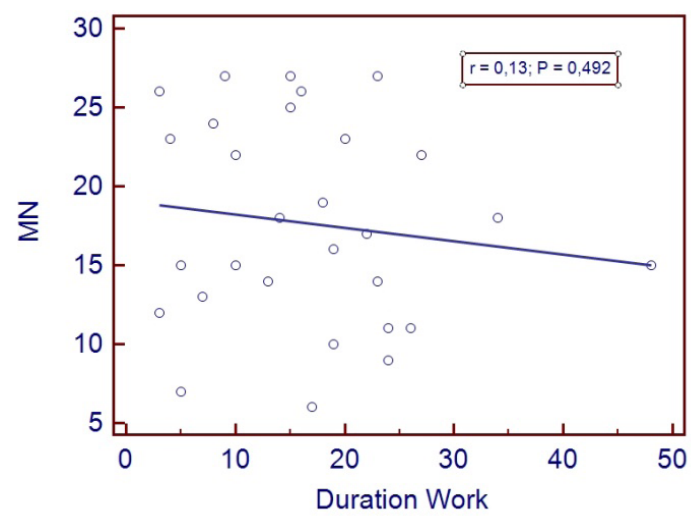

Figure 6. The mean frequencies of micronuclei in medical radiation workers based on working duration

In the present work according to work duration of employment the mean frequencies of $\mathrm{MN}$ were no significant correlation was observed between exposing group compared to the control group as shown in Fig. 6, (Andreassi et al., 2005) reported the similar result that was no significant correlation between occupational radiation doses during the past year and $\mathrm{MN}$ frequency. (Zakeri \& Hirobe, 2010) also reported that no obvious trend of increased chromosomal damages as a function of either duration of employment, exposed dose, sex or age. Rapolo et al. (2012) also reported that length of work does not affect the extent of genetic damage induced by chronic exposure to ionizing radiation, but an increased frequency of binucleated and mono-nucleated cells with micronuclei was observed, based on the accumulated radiation dose.

Based on the research result it can be pointed out that although at low-level radiation exposure, unstable aberrations (such as dicentric and rings) could not be detected, the analysis of $\mathrm{MN}$ in cytokinesis-blocked binucleated cells were the most sensitive biomarker to evaluated early clastogenic effect induced by low chronic radiation exposure, even though the absorbed doses calculated for the exposed individuals were below the permissible limit. In order to monitoring, detection of early genotoxic effects may allow for the adoption of preventive biological control measures, such as reduction of hours of occupational exposure. Because of the sensitivity of the CBMN assay for low-dose detection, in the future research needs to be done by combining the assay with fluorescence in situ hybridization centro- mere staining technique. Referring to Vral et al. (2011) the development of a combined automated $\mathrm{MN}$-centromere scoring procedure remains a challenge for the future, as it will allow systematic biomonitoring of radiation workers exposed to low-dose radiation.

\section{CONCLUSIONS}

In conclusion chronic low radiation dose exposure in medical workers was not significantly affect on lymphocytes proliferation. Further research using larger sample number should be conducted to ensure the effect of chronic low radiation dose exposure on lymphocytes proliferation. Micronuclei in cytokinesis-blocked binucleated cells demonstrated to be the most sensitive biological marker to determine the cellular response to low levels of irradiation. It is important to develop procedures that allow the occupationally exposed hospital staff to be biomonitored and protected from ionizing radiation.

\section{ACKNOWLEDGMENTS}

The authors gratefully acknowledge to Center for Technology of Radiation Safety and Metrology (PTKMR). This research was supported by grants from the National Nuclear Energy Agency of Indonesia (Badan Tenaga Nuklir Nasional) as a BATAN Annual Research Project in 2015.

\section{REFERENCE}

Agency, International Atomic Energy Agency. (2011). Cytogenetic Dosimetry: Applications in Preparedness for and Response to Radiation Emergencies. Manual Series 247.

Alakoç, C. \& Eroğlu, H. E. (2011). Determining Mitotic Index in Peripheral Lymphocytes of Welders Exposed to Metal Arc Welding Fumes. Turkish Journal of Biology, 35(3), 325-330.

Andreassi, M. Cioppa, A., \& Botto, N. (2005). Somatic DNA Damage in Interventional Cardiologists: A Case-Control Study. FASEB Journal, 17(3), $1-17$.

Boffetta, P., van der Hel, O., Norppa, H., Fabianova, E., Fucic, A., Gundy, S., ... \& Kelecsenyi, Z. (2006). Chromosomal aberrations and cancer risk: results of a cohort study from Central Europe. American journal of epidemiology, 165(1), 36-43.

Bonassi, S., Znaor, A., Ceppi, M., Lando, C., Chang, W. P., Holland, N., ... \& Bigatti, M. P. (2007). An Increased Micronucleus Frequency in Peripheral Blood Lymphocytes Predicts the Risk of Cancer in Humans. Carcinogenesis, 28(3), 
$625-31$.

Bouraoui, S., Mougou, S., Drira, A., Tabka, F., Bouali, N., Mrizek, N., ... \& Saad, A. (2013). A cytogenetic approach to the effects of low levels of ionizing radiation (IR) on the exposed Tunisian hospital workers. International journal of occupational medicine and environmental health, 26(1), 144-154.

Cardoso, R. S., Takahashi-Hyodo, S., Peitl, P., Ghilardi-Neto, T., \& Sakamoto-Hojo, E. T. (2001) Evaluation of chromosomal aberrations, micronuclei, and sister chromatid exchanges in hospital workers chronically exposed to ionizing radiation. Teratogenesis, carcinogenesis, and mutagenesis, 21(6), 431-439.

Cigarrán, S., Barquinero, J. F., Barrios, L., Ribas, M., Egozcue, J., \& Caballin, M. R. (2001). Cytogenetic analysis by fluorescence in situ hybridization (FISH) in hospital workers occupationally exposed to low levels of ionizing radiation. $R a$ diation research, 155(3), 417-423.

Dias, F. L., Antunes, L. M., Rezende, P. A., Carvalho, F. E., Silva, C. M., Matheus, J. M., ... \& Balarin, M. A. (2007). Cytogenetic analysis in lymphocytes from workers occupationally exposed to low levels of ionizing radiation. Environmen tal toxicology and pharmacology, 23(2), 228-233.

Eroğlu, H. E. (2011). The Cytogenetic Effects of Black Tea and Green Tea on Cultured Human Lymphocytes. Brazilian Archives Of Biology And Technology, 54(6), 1159-65.

Fenech, M. (2007). Cytokinesis-block micronucleus cytome assay. Nature protocols, 2(5), 1084-1104.

Joseph, L. J., Patwardhan, U. N., \& Samuel, A. M. (2004). Frequency of micronuclei in peripheral blood lymphocytes from subjects occupationally exposed to low levels of ionizing radiation. Mutation Research/Genetic Toxicology and Environmental Mutagenesis, 564(1), 83-88.

Kašuba, V., Rozgaj, R., \& Jazbec, A. (2008). Chromosome aberrations in peripheral blood lymphocytes of Croatian hospital staff occupationally exposed to low levels of ionising radiation. $A r$ chives of Industrial Hygiene and Toxicology, 59(4), 251-259.
Kurnia, I., Bintari, S. H., \& Khaisuntaha, M. (2012). Tingkat Keganasan Kanker Serviks Pasien PraRadiasi Melalui Pemeriksaan AgNORs, MIB-1 dan Cas-3. Biosaintifika: Journal of Biology \& Biology Education, 4(2), 53-61.

Lusiyanti, Y., Alatas, Z., Syaifudin, M., \& Purnami, S. (2016). Establishment of a dose-response curve for X-ray-induced micronuclei in human lymphocytes. Genome integrity, 7(49), 1-4.

Lusiyanti, Y., Alatas, Z., Lubis, M., Suvifan, V. A., Ramadhani, D., \& Purnami, S. (2013). Doseresponse curve of chromosome aberrations in human lymphocytes induced by gamma-rays. Atom Indonesia, 39(3), 124-128.

Maffei, F., Angelini, S., Forti, G. C., Lodi, V., Violante, F. S., Mattioli, S., \& Hrelia, P. (2002). Micronuclei frequencies in hospital workers occupationally exposed to low levels of ionizing radiation: influence of smoking status and other factors. Mutagenesis, 17(5), 405-409.

Terzoudi, G. I., \& Pantelias, G. E. (2006). Cytogenetic methods for biodosimetry and risk individualisation after exposure to ionising radiation. Radiation protection dosimetry, 122(1-4), 513-520.

Thierens, H., Vral, A., Barbe, M., Meijlaers, M., Baeyens, A., \& Ridder, L. D. (2002). Chromosomal radiosensitivity study of temporary nuclear workers and the support of the adaptive response induced by occupational exposure. International journal of radiation biology, 78(12), 1117-1126.

UNSCEAR (United Nations Scientific Committee on the Effects of Atomic Radiation). Sources and Effects of Ionizing Radiation. Report to the General Assembly, (2000); Volume II: Effects. New York: United Nations.

Vral, A., Fenech, M., \& Thierens, H. (2011). The micronucleus assay as a biological dosimeter of in vivo ionising radiation exposure. Mutagenesis, 26(1), 11-17.

Zakeri, F., \& Hirobe, T. (2010). A cytogenetic approach to the effects of low levels of ionizing radiations on occupationally exposed individuals. European journal of radiology, 73(1), 191-195. 